\title{
Research on Current Situation of Rural Sports Public Service in Hebei Province
}

\author{
Yan $\mathrm{Li}^{12}$ \\ ${ }^{1 .}$ Hebei Institute of Physical Education 050041, \\ 2. Institute of Physical Education, Hebei Normal University050024 \\ 82 Xuefu Road, Shijiazhuang, Hebei 050041 China \\ Email: 878578182@qq.com
}

\begin{abstract}
This paper starts from the development and existing problems of the rural sports public system in our province, and analyzes the construction of the rural public service system in our province, summarizes the existing problems and deficiencies of the rural public service system construction in our province, combines the specific situation in our province with the domestic and international advanced experience, and proposes further innovation and perfect countermeasures of the rural public service system in our province from the following aspects, for instance, the government plays a leading role, guides a wide range of investment from society, and strengths the fitness instruction and promotes the constructions of sports brands.
\end{abstract}

Keywords-Hebei province; rural areas; sports public service; current situation; research

Sports Bureau in Hebei province has always increased the support on the sports infrastructure in rural remote areas through the snow-charcoal project, outdoor activity base and the support of body-building brands, and vigorously advocated to combine with the local reality and plan to promote the construction of the rural sports public service system. The reform and improvement of the rural sports public service not only improves the physical quality of the farmers, but also further promotes the social harmony and the overall construction of a well-off society.

\section{- I. DEVELOPMENT OF RURAL SPORTS PUBLIC SERVICE SYSTEM IN HEBEI PROVINCE}

A. The institutional guarantee of the construction of sports public service system in Hebei province

Hebei province has successively issued a series of laws and regulations to promote the rapid development of sports cause, especially in recent years, "the $12^{\text {th }}$ Five-year Development Program of Modern Service Industry in Hebei Province", "Suggestions on Implementation about Promoting the Development of Cultural Industry”, “ Suggestions on Implementation about Speeding up the Development of Sports Industry Issued by the General Office of People's Government in Hebei Province", and "Suggestions on Implementation about Development Planning of Leisure Tourism Industrial Belt around Beijing and Tianjin have been issued in succession. In 2011, Hebei province promulgated "Implementation Plan of National Fitness in Hebei Province (2011-2015)", defined the target tasks, strengthened the work measures, indicated the direction on further improvement of sports public service system, and provided the policy support. At the beginning of 2013, the general office of the provincial government issued "Suggestions on Key Work Arrangement for Sports in Hebei Province during Three Years (2013-2015)"; the sports work was written into Report on Governmental Work of provincial government every year; the national fitness cause was incorporated into the development planning of national economy and society of the governments at all levels, both provincial and municipal governments incorporated the national fitness funds into the government finance.

B. The construction of the rural sports public service facilities

Sports facilities are the foundation of the construction of rural sports public service system; based on meeting the diversified and personalized fitness demands of the broad masses, Hebei province gave great impetus to promote the construction of the sports fitness facilities in accordance with the "small type, diversified and practical" principle. So far, the national fitness project of the villages affiliated to the villages and towns have achieved the full coverage. The peasant sport fitness project themed as "Hundred Counties, Thousands of Villages and Townships" has only covered 30,000 villages, accounting for $57 \%$ of the number of the existing villages in the whole province; "Snow-charcoal Project" fundamentally improved the backwardness of the sports facilities in 18 impoverished counties; and 44 national fitness outdoor bases of "Leisure Tourism Industrial Belt around Beijing and Tianjin" were established. The national fitness centers at all towns and the projects of fitness field are in steady progress, and the fitness projects in villages and towns cover the administrative villages affiliated to all villages and towns in the whole province.

C. The rural physical fitness activities have become increasingly abundant.

Hebei province incorporates the sports funds, capital construction funds of sports and the public sports facilities construction into the planning of national economic and social development at the corresponding level, and includes the sports funds into the financial budget at the corresponding level, further improves the policies which support the development of sports cause in finance, banking, tax policy, land, energy, etc. Hebei province also actively creates the network of fitness organizations which take the villages and towns 
(administrative villages) as the units, take the fitness instruction stations, recreational and sports activity stations, morning and evening exercise spots which directly serve to people as the emphasis. The county-level national fitness joint conference is under construction at a high speed. In 2012, there were more than 1,100 municipal and county-level sports associations. The coverage rate of the grass-roots sports organizations in villages and towns was increased by $8 \%$ in comparison with that at the end of the " $10^{\text {th }}$ Five-year Plan" and basically formed the situation that "peasants' fitness is dependent on the village committee, students' fitness is dependent on school, and fitness of project enthusiasts is dependent on the professional association and club". It has become a trend that farmers spontaneously hold the fitness activities.

\section{- II. THE EXISTING PROBLEMS IN THE DEVELOPMENT OF RURAL SPORTS PUBLIC SERVICE SYSTEM IN HEBEI PROVINCE}

Through long-term development, all the basic conditions of the rural sports pubic service system in Hebei province have improved a lot; however, the deep-rooted contradictions and problems which have restricted the construction of the rural sports public service system for a long time have gradually appeared, and mainly reflected in the following aspects:

\section{A. The sports public services are in short supply.}

There are some structural and institutional obstacles for the governments at all levels when performing the function of the public sports service; including the insufficient service and amount of the public sports, and the worse public welfare; the most prominent obstacles focus on the seriously inadequate social supply, the insufficient diversified fitness facilities, the sound fitness organizations and the personalized fitness guidance, etc. According to the situation in our province, at the end of 2011 , the sports facilities in more than $40 \%$ counties were still inadequate; the varieties of sports facilities configured for rural areas were not abundant, and the standards were lower in general. The networks of sports organizations were imperfect. At present, according to the situation of the county-level sports administrative departments in Hebei province, only one country established the independent sports bureau (others are incorporated with culture sector, broadcasting and TV, press and publications, etc.); moreover, the proportion that the fitness organizations at all levels master the sports skills is low. Those who often participate in physical exercises only accounted for $30.4 \%$ in 2010 ; and the level of the supply is not high. The basic sports rights and interests related to the vital interests of the masses are still prominent.

\section{B. The sports investment mechanism is not perfect.}

Government financial investment is the main form of sports public service system construction. The investment from private and non-governmental organizations in our province is in low proportion, the methods of encouraging and mobilizing the social forces to support sports are few; and the means of utilizing the policy levers to mobilize social forces are not adept. Compared with other provinces and cities, among 23 provinces (cities and districts) through statistics, the national fitness expenditure in our province ranked the last three. So far, there have been more than 40,000 sports venues in Hebei province, including more than 28,000 from education system, accounting for more than $70 \%$; less than 1,000 from sports system, accounting for only a bit more than $2 \%$; and more than 11,000 from other systems, accounting for about $27 \%$; in the existing more than 40,000 sites, the rural proportion is very little; meanwhile, the majority of venues don't come into play, and the efficiency of sports facilities is not ideal.

\section{The unbalanced development between urban and rural areas}

The number of urban residents in our province who participate in physical exercise is higher than $20 \%$; the sports facilities used by urban residents are significantly superior to that in rural areas; in terms of sports consumption, take Shijiazhuang as an example; in 2009, the expenditure of urban residents on sporting goods and fitness activities is 44.29 Yuan, but the expenditure of rural residents are les than 20 Yuan. In terms of training the social sports instructors, most of the social sports instructors come from the towns at or above the county level, accounting for almost $50 \%$ of the population in the rural areas; the proportion of social sports instructors is very low, and far less than the standards of 1 social sports instructor in 2000 people. In terms of the organizational activities, more than 120 large-scale activities are held in cities by our province, and some activities are sponsored by the funds from government investment; and most rural areas are lack of the capital support. In terms of the fitness organizations, among about 1,100 social organizations in our province, including the sport federation, and all the sports associations with a variety of sports, due to leisure time, living habits, hobbies and geographical conditions, a few farmers are involved with some associations.

\section{- III. THE COUNTERMEASURES OF DEVELOPMENT OF RURAL SPORTS PUBLIC SERVICE SYSTEM IN HEBEI PROVINCE}

\section{A. Make a plan on rural public sports facilities}

Insist on high-standard stance and high-starting-point plan, fully learn from the advanced concepts and successful practices from brother provinces and cities in this aspect, broaden the vision and mind scope, earnestly formulate a Construction Planning of Rural Public Sports Facilities which is suitable for the reality in Hebei province, and provide the scientific basis and practical guarantee for participating in the rural public sports facilities construction in the whole province. Meanwhile, incorporate all kinds of rural sports public service facilities into the assessment index system that the construction of villages and towns must be improved, speed up the construction process of rural sports facilities, improve the construction standard and level of rural public sports facilities.

\section{B. Accelerate the improvement of the urban and rural grassroots sports organizations}

Sports organization is not only an important carrier for 
the masses to participate in the national fitness, but also the important force to promote the implementation of "National Fitness Plan". It is essential to increase the sports organizations rapidly, especially the grass-roots sports organizations, improve the service quality of the fitness organizations, strengthen the management of public sports organizations and sports teams, help the spontaneous sports groups to strengthen self organization and management ability.

C. Strengthen the construction of urban and rural grass-roots sites

Focus on the communities, villages and towns, organs and enterprises and public institutions, speed up the constructions of fitness instruction stations, recreational and sports activity stations, morning and evening exercise sports which directly serve to people. The sports organizations are completed in the urban streets, villages and towns; more administrative villages are equipped with the sports fitness stations, and the community sports clubs are built in urban communities. Focus on the communities, villages and towns, organs and enterprises and public institutions, fully implement "five-one project" of the grass-roots fitness station (once a grass-roots station is built, one social sports instructor is allocated, one fitness team is established, one leading project is cultivated, and the national fitness activity must be held once a year at least), strengthen the standardized management of the grass-roots station, guide the healthy development of the grass-roots organizations.

D. Establish and improve the information feedback mechanism of the grass-roots sports departments

Establish the smooth information feedback mechanism between the sports administrative department and the pubic demands, so as to form the institutionalized information acquisition and feedback system, master the latest public demand information, provide the first-hand information for policy formulation and implementation, and provide more scientific and effective sports public services for the masses.

\section{- REFERENCES}

[1] State General Administration of Sports. 12 $2^{\text {th }}$ Five-year Development Plan of Sports Cause [Z]. 2010

[2] Sports Bureau of Hebei province. Hebei province- Sports Magazine [Z]. 2011

[3] Liu Mingsheng, Li Jianguo. Construction of sports public service system in the perspective of new public service thoery [J]. Journal of sports scientific research. 2010.31

[4] Zheng Jiakun. Some thoughts on constructing Chinese public sports service system in " $12^{\text {th }}$ Five-year" period [J]. Journal of Chengdu Sport University. 2011.12

Li Yan (1979 - ), Associate professor, doctoral candidates, Research Interests: Sociology of Sport.

The survey subject of investigating the people's livelihood with the social development in Hebei province Serial number: 201301213 